\title{
The Impact of Recreational Motor Story in the Development of Innovative Thinking in Kindergarten
}

\author{
Mohamed Omar Abdelrassoul Abdullah ${ }^{1}$ \\ ${ }^{1}$ Lecturer in Curriculums \&teaching Methods of Physical Education
}

\begin{abstract}
Research aims to identify the impact of recreational motor story in the development of innovative thinking in kindergarten, the researcher used experimental method, and sample volume (50) children are distributed equally, and one of the most important results of recreational use of kinetic story concerns a positive influence on the thinking of innovation (Fluency-flexibility-authenticity) among the experimental sample of research.
\end{abstract}

Keywords: motor story-recreation-innovative thinking-fluency-flexibility-authenticity

\section{Introduction:}

K indergarten for stage $4-6$ years of milestones in human life, where this character in some mental and psychological and social potential in children, has won this stage in Eastern and Western societies, although a The trends towards what goes where educational processes but clear agreement as a great influence on the important next stages, with increasing kindergartens Arabic Republic of Egypt had to be interest in a program that taught to this point with a view to raising children physically, morally, psychologically and mentally.

Recreational sports is one of the areas that help build your child's personality, what gives him/her opportunities to express himself and his abilities and his creations, and it's a rich area activities that satisfy the child's need for urgent action and reflection and creativity, which acquired through fitness and psychological practice Physiological and skill, Mohamed Elhamahmy and Aida Abdel Aziz (1998) indicate that recreation provide children with experiences and information by automated methods (18:160) Tahany Abdel Salam (2000) adds that recreational activities help to feel happiness, joy and pride to accomplish work Tahany Mohamed Abdel Salam: 245)(

Sports recreation has different types of recreational programs, there is no doubt that for the disabled the right to practice all kinds of recreation, recreational and educational psychologists and researchers in the field of disability to develop a set of psychological foundations that must be followed by working with the disabled in general and mentally handicapped in particular to reduce the psychological effects which need try to integrate disabled persons into society so they don't feel lonely and isolated and give him confidence in himself and create the circumstances that prompt them to participate in various and diverse programs provided to them Hanan Fayez Mahmoud Makhyoun : (41-42)

Through reading and search noted that most research has focused on recreational activities and their impact on the different origin misfits, while rarely eating for recreational activities and their effect on the mentally handicapped and especially in the sport of gymnastics, and faith, a researcher with the importance of recreational motor story for children of kindergartens which raised researcher thought about dealing with a problem that she saw from his point of view they are rare in public recreational area.

They try to apply a sport recreation program at kindergarten and see how it affected our innovative thinking, fit multiple types of kinematic simple promotional stories, nature and mentality, nature and trends of children in this stage, simply its laws and simply performed and places Its practice.

Through the work of the researcher as a staff member, Department of curriculum and instruction making it up to different levels of education, including kindergarten teachers ' accreditation has noted in a way traditional education and neglect education using recreational motor story researcher also noted the low level of Innovative 
thinking of the children, so that children's stage featuring children love to poll and innovation which requires teaching staff attention at this point, so the view finder using recreational motor story to learn about its effect on the development of creative thinking (fluency - flexibility - authenticity) in kindergarten.

Objectives of the research: the research aims to identify the impact of recreational motor story in the development of innovative thinking in kindergarten and to achieve that you must achieve the following goals:

*The impact of recreational motor story on innovative thinking (fluency - flexibility - authenticity) in kindergarten.

* learn the differences between the pre-post measures with control group and experimental the in innovative thinking (fluency - flexibility -

authenticity ) in kindergarten

\section{The Hypothesis:}

1-There is a significant statistical differences between pre-post measures with the experimental group in the innovative thinking (fluency - flexibility - Authenticity ) in kindergarten favor to the post measure.

2-There is a significant statistical differences between the two post measures with the control \&experimental groups in the innovative thinking (fluency - flexibility authenticity) in kindergarten favor to the post measure with the experimental group.

\section{The research terms:}

\section{Motor story:}

Represent a unit of exercises and movements integrated non-formal and simple. Elin Wadeea Farag: (24)

\section{Recreational activity:}

A work to increase emotional reaction or mood or feeling you felt before, during and after the exercise of the activity or negatively or inventive, it is purposeful and building and during leisure time (Tahany Mohamed Abdel Salam: 13)

\section{Innovative thinking:}

It is the grade the child has earned through his respond to innovative thinking test for Torrance in the high light of innovative thinking abilities included (fluency - flexibility - authenticity)(Fink .L.Dee 2005 :125)

Authenticity: Is the ability to produce new, unknown or unfamiliar ideas upon others.
Fluency: Is the ability to produce as many of the ideas associated with the situation or problem.

Flexibility: Is the ability to produce various ideas or use different ways of dealing with problems.

\section{Research procedures:}

\section{The method:}

The researcher has utilized the experimental method with one experimental group design, and carried out the prepost measures because of its appropriate to the research problem.

\section{The sample:}

The sample consisted of initial research (75) children for the school year (2016/2017) after excluding children not attending and the sample was divided into 25 children experimental group, (25) a child of the control group, in addition to (25) of the scoping study

\section{Data collection tools:}

The researcher has selected tools and appropriate tests for a theme based on experts opinions and use references and previous studies were as follows

\section{:Devices and Boards}

* Stopwatch to measure time in second.

* Collars are different sizes.

*Various Swedish seats - core plastic colors balls and different sizes.

* Geri to draw lines, circles and triangles on the floor.

* $20 \mathrm{~cm}$ height boxes - sponge mattresses - grain bagschairs.

*Colorful balloons-buzzer-Tennis balls- colored streamers.

\section{The researcher has utilized the following tools:}

\section{*An innovative thinking scale:}

Torrance innovative thinking scale was utilized -translated by Abdullah Soliman, FoadAbou Hattab, it is one of the most famous important scale, which measures this ability in different learning stages from nursery to university, the picture(A) was utilized from forms test, the test consisted of three activities through 30 minutes, the children are asked to compose the picture by painting (in the first activity)this activity arise authenticity and in detailed, in the second/third activity (the uncompleted forms-frequent forms)to arise different types of fluency - flexibility authenticity. 


\section{Parity and groups:}

The researcher as applied Torrance verbal tests and forms (A) on the experimental/control groups, grades means were calculated and standard deviation, (T) value for differences between means, as it illustrated in table(1)

Table (1)

T Value for differences between means for innovative thinking tests For experimental/control groups N1=N2=25

\begin{tabular}{|c|c|c|c|c|c|c|}
\hline \multirow{2}{*}{$\begin{array}{l}\text { Statistical variables } \\
\text { Innovative thinking }\end{array}$} & \multirow{2}{*}{ Type } & \multicolumn{2}{|c|}{ Experimental } & \multicolumn{2}{|c|}{ Control } & \multirow{2}{*}{ T Value } \\
\hline & & $\mathbf{S}$ & $\mathbf{A}$ & $\mathbf{S}$ & $\mathbf{A}$ & \\
\hline \multirow{2}{*}{ Fluency } & verbal & 43,9 & 8,01 & 43,8 & 7,05 & 0,06 \\
\hline & formalist & 32 & 3,68 & 32,02 & 3,52 & 0,08 \\
\hline \multirow{2}{*}{ Flexibility } & verbal & 24,1 & 2,91 & 24,24 & 2,56 & 0,18 \\
\hline & formalist & 22,4 & 3,03 & 22,30 & 3,10 & 0,11 \\
\hline \multirow{2}{*}{ Authenticity } & verbal & 32,7 & 6,9 & 32,65 & 6,72 & 0,03 \\
\hline & formalist & 33,71 & 4,01 & 33,51 & 4,13 & 0,17 \\
\hline
\end{tabular}

*T Table with significant $0.05=1,711$

Table(1) shows that there is a statistic significant differences between grades means for the experimental/ control group in the innovative thinking scale and branched tests ,(fluency - flexibility - authenticity)

The scientific transactions of Torrance Scale:

The stability:
The stability coefficient of the scale under discussion was calculated by applying and repeat it on the exploratory sample with a time apartheid 2 weeks, the correlation coefficient between the first/ second apply was found, through the period from to and table (2)illustrates it.

Table (2)

The stability coefficient for Torrance Scale for Verbal Innovative Thinking and forms with a repeat test method (N=25)

\begin{tabular}{|c|c|c|}
\hline Test Type & The skill & The stability coefficient \\
\hline \multirow{4}{*}{ Verbal } & Fluency & 0,58 \\
\cline { 2 - 3 } & Flexibility & 0,63 \\
\cline { 2 - 3 } & Authenticity & 0,56 \\
\hline \multirow{3}{*}{ Formalist } & Fluency & 0,62 \\
\cline { 2 - 3 } & Flexibility & 0,57 \\
\cline { 2 - 3 } & Authenticity & 0,59 \\
\hline
\end{tabular}

This table(2) shows that Torrance stability coefficient concerning re-apply was in between $(0,56-0,63)$ concerning forms test it was between $(0,57-0,62)$ it was accepted for test stability

\section{Graders Honesty}

The researcher has utilized graders honesty the measure results was presented to (3)graders, the correlation coefficient was found between every grader and the other, table (3)illustrates it.

Table (3)

The validity coefficient for Torrance innovative thinking "verbal \&formalist" Scale $(A, B)(N=25)$

\begin{tabular}{|c|c|c|c|}
\hline \multirow{2}{*}{$\begin{array}{c}\text { Grading } \\
\text { Coefficient }\end{array}$} & $\begin{array}{c}\text { Correlation Coefficient between grades } \\
\text { of the first grader and the second }\end{array}$ & $\begin{array}{c}\text { Correlation Coefficient between grades } \\
\text { of the first grader and the third }\end{array}$ & $\begin{array}{c}\text { Correlation Coefficient between grades } \\
\text { of the second grader and the third }\end{array}$ \\
\cline { 2 - 4 } & 0,865 & 0,84 & 0,811 \\
\hline
\end{tabular}

The table(3)shows that the correlation coefficients between all of graders significant with $(0,05)$ which indicates to the scale validity

\section{The recreational motor story Apply:}

The aim of applying The recreational motor story
The utilizing of The recreational motor story has a positive effect on the innovative thinking level with kindergarten.

\section{The suggested programs establishing:}

After reading previous scientific researches\& references in the same field of the current study, interviews with professionals, we can identify the major principles to set 
the program, devices \&tools utilized, the program aims was identified in:

Develop the learning process for the child from all sides as general*

*The teacher must exclude to do his educational roles such as orienting, guiding and help.

*Give attention to cooperation among children

*Learning must be active with interaction in a democratic atmosphere

*Develop, improve skills related to teaching

\section{Basis of Recreational motor story preparing:}

The researcher prepared programs in the high light of the following basis:

-Be appropriated the recreational unit content with the innovative thinking of the children

-Prepare a recreational motor stories grading in difficulty

-Flexibility \&diversity of program , including definite tasks, with concerning individual differences.

\section{Programs Time distribution:}

Applying programs has 8 weeks, two units weekly totally (16) learning unit, the unit time (45) minutes according to the study system distributed as follow:

-(10)m administrative works, general physical preparation

-(30)m the major part, divided to

-(10)m review all preceding

$-(20) m$ the recreational motor story

$-(5) \mathrm{m}$ the final part.

The program content:
By reading scientific references, previous studies, we can excluded a group of recreational motor stories appropriated to the research aim and sample properties.

\section{(The exploratory study)}

It was carried out on (10) children from the same research community, out of the major sample, the apply was in the day of // for experiment two units of the recreational motor story to recognize:

The appropriating of unit content to the unit time

The ease of applying the recreational motor story

The results:

The appropriating of unit content to the unit time

The recreational motor story appropriated to the unit aim.

\section{The post measures:}

It was conducted for the research two groups (the experimental one-the control one) in the period of / / to / / with the same order of the pre measures.

The statistical transactions:

The researcher utilized SPSS to carry out the statistical transactions appropriated to the research nature, with using:

-Mean, Standard Deviation, Median- Torsion coefficient

-Pearson Correlation Coefficient - T Test

\section{Results discussion:}

First: Results presentation:

Differences between pre-post measures for the experimental group in the innovative thinking (Fluency-flexibility-authenticity0 with kindergarten

Table (3)

Significance of differences between grades means of the experimental group in the innovative thinking in pre-post measures $(\mathbf{N}=\mathbf{2 5})$

\begin{tabular}{|c|c|c|c|c|c|c|}
\hline \multirow{2}{*}{ Variable } & \multirow[t]{2}{*}{ Type } & \multicolumn{2}{|c|}{ pre } & \multicolumn{2}{|c|}{ Post } & \multirow[t]{2}{*}{ T Value } \\
\hline & & $\mathbf{S}$ & $\mathbf{A}$ & $\mathbf{S}$ & $\mathbf{A}$ & \\
\hline Fluency & Verbal & 43,9 & 8,01 & 75,2 & 6,32 & $* 15,627$ \\
\hline \multirow{2}{*}{ Flexibility } & Verbal & 24,1 & 2,91 & 38.3 & 4,56 & $* 13,76$ \\
\hline & Formalist & 22,4 & 3,03 & 31,1 & 4,01 & $* 9,88$ \\
\hline Authenticity & Formalist & 33,71 & 4,01 & 52,43 & 7,09 & $* 10,99$ \\
\hline
\end{tabular}

*T Table with $0,05=1,711$ 
Table (3) shows, with comparing calculated ( $\mathrm{T}$ ) Table, all values are statistically significant with $(0,05)$ favor to post measure $\mathrm{m}$, which indicates the effectiveness of the recreational motor story

The table clarified that the recreational motor story with its various activities led to developing the innovative thinking with the experimental group, the means of research sample grades in verbal \&formalist fluency skill frequently for the experimental group $(43,9-75,2),(32-37,2)$ the verbal \&formalist flexibility was(38, 3-24,1)

$(22,4-31,1)$ the verbal \&formalist authenticity was $(32,7-$ $61,3),(33,71-43,52)$ all of it was significant with $(0,05)$ favor to post measure, which indicates to the efficiency of the recreational motor story to make significant difference in pre-post measures

Table (4)

Differences significances between means of grades of the experimental group in the innovative thinking in pre-post measures

$(\mathbf{N}=\mathbf{2 5})$

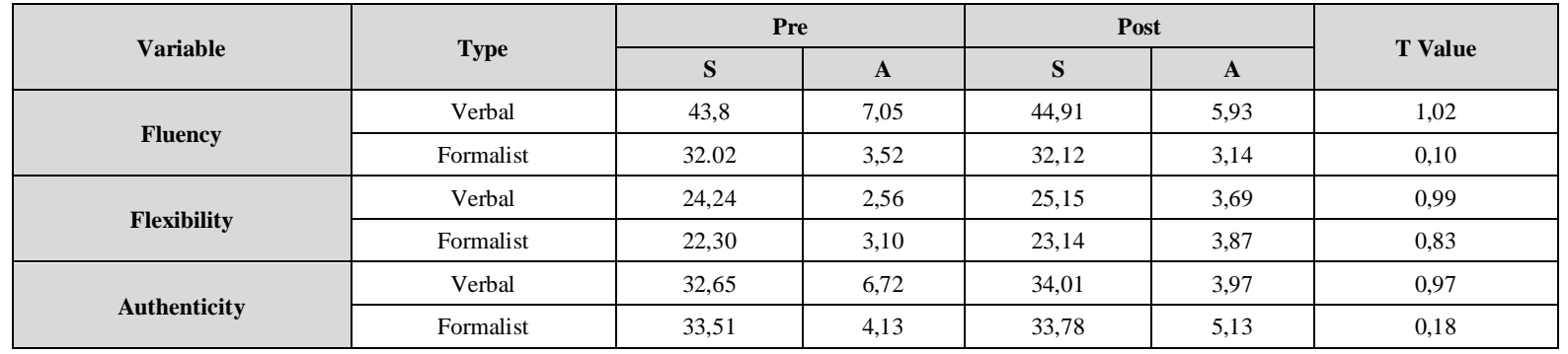

T table with $0,05=1,711$

Table (4) illustrates that there is no significant statistical differences between means of grades of the experimental group in the innovative thinking scale and the branched test were(Fluency-flexibility- Authenticity)

Differences between the two post measures with the experimental group and control group in the innovative thinking (fluency- flexibility- authenticity) with kindergarten

Table (5)

Differences indications between means of experimental group \& control group in innovative thinking in post measure $\mathrm{N1}=\mathrm{N} 2=25$

\begin{tabular}{|c|c|c|c|c|c|c|}
\hline \multirow{2}{*}{ Variable } & \multirow{2}{*}{ Type } & \multicolumn{2}{|c|}{ Experimental } & \multicolumn{2}{|c|}{ Control } & \multirow{2}{*}{ TValue } \\
\hline & & $\mathbf{S}$ & $\mathbf{A}$ & $\mathbf{S}$ & $\mathbf{A}$ & \\
\hline \multirow{2}{*}{ Fluency } & Verbal & 75,2 & 6,32 & 40,91 & 5,93 & $* 20,15$ \\
\hline & Formalist & 37,2 & 2,11 & 32,12 & 3,14 & $* 10,91$ \\
\hline \multirow{2}{*}{ Flexibility } & Verbal & 38,3 & 4,56 & 25,15 & 3,69 & $* 15,65$ \\
\hline & Formalist & 31,1 & 4,01 & 23,14 & 3,87 & $* 9,07$ \\
\hline \multirow{2}{*}{ Authenticity } & Verbal & 61,3 & 6,87 & 34,01 & 3,97 & $* 18,05$ \\
\hline & Formalist & 52,43 & 7,09 & 23,78 & 5,13 & $* 14,54$ \\
\hline
\end{tabular}

*T table value with significance $0,05=1,711$

Table (5) clarified that in comparison calculated (T) and (T)table, all values is statistically significant with $(0,01)$ favor to the experimental group which indicates to the efficiency of the recreational motor story.

The previous table illustrates that the recreational motor story including various activities led to develop the innovative thinking with the experimental group ,the grades means of verbal\& formalist fluency skill frequently -with experimental \&control group $(75,2-40,91)-(37,2-$ 32,12 )
The verbal\& formalist flexibility was $(38,3-26,15),(23,14-$ $31,1)$, while the verbal\& formalist authenticity was(34,1$61,3),(23,78-52,34)$ all of those values is significant with $(0,05)$ favor to the experimental group, which proved the efficiency of the recreational motor story in making significant difference between the experimental \&control group.

Table (3) clarified that there is a significant statistical differences between pre-post measures in the innovative thinking scale and the branched tests, it was(fluencyflexibility- authenticity)favor to the post measure, which indicates to the efficiency of the recreational motor story. 
While table (4) clarified that there is no significant statistical differences between the pre-post measures with the control group in the innovative thinking scale and the branched tests, it was(fluency-flexibility- authenticity) the researcher attributes these results to the positive effect of the recreational motor story utilized in the research.

Table (5) clarified that there is a significant statistical differences between the two post measures of the experimental/control group in the innovative thinking scale and the branched test it was fluency-flexibilityauthenticity)favor to post measure of the experimental group, which proves the efficiency of the recreational motor story. The researcher reported that the reason of this development was because many factors :

*Planning for the suggested program in an integrated form aiming to develop studying and innovative thinking during teaching that is from:

A- Aims: Identifying the behavioral aims helped in recognizing of children of it to develop children abilities of innovative thinking, activate their fancy, cooperate children with each others in presenting the program efficiency and positively, and our desire to know more about learning.

B-The content : the program content was presented in a form of objectives realizing depth and wideness in the learning program as in lectures for all children , arrange it in a logic way to be variety, connected, serial logically.

C- Learning \&teaching methods :The recreational motor story was utilized for learning, which helped in develop the innovative thinking with children .The result agreed with many educational opinions indicating to the effectiveness of those methods in increasing studying with Ibrahim Alharthy 2001, Abdulsalam Moustafa 2001, Hassan Zaytoun 2002, Soha Mohamed Fekry 2005.

D-Tools, Learning activities :the researcher has utilized many various materials, learning, sport tools, which helped in improving learning process, using tools with a new, creative ideas, helped in developing study and innovative thinking.

The results agreed with Shaffer (1998) about the effectiveness of utilizing modern, various tools, boards in teaching programs for developing the innovative thinking.

E- The logic serial of objectives of program and practical activities: which work to encourage children to search and discover which contributes in increasing the cognitive bag and deep concepts, information, debate ideas, discuss it widely to go out traditional frames in thinking in a democratic atmosphere away from threaten, ideas blackout.

F- Work in groups :Helped in cooperation, interaction among the group individuals in perception knowledge , new ideas, encourage dialogue, discussion in all ideas under discussion.

The recreational motor story for innovative thinking through the subject: Utilizing recreational motor story made the innovative thinking as a major part of the subject as a tool of its learning and teaching, which gave the opportunity for the experimental group individuals to practice innovative thinking in a good form.

The result of the current study agreed with both of Laila Karam (2002) , Mohamed Abdulrahim Ads(2006) , Kenneth(2003), Yann (2000).

The researcher attributes results the program apply in which distinguished with express freedom, continuous interaction among children in a practical situations, permit the children to discuss and know and participate in preparing available tools, produce various ideas, which gave the children the opportunity to review their thinking and made them compose relations, suppose hypothesis, organize data, design, experiment, noting, resulting , giving different ideas -not typical toward the request or the sub-theme of learning process.

Renzulli.2004 described the creative person that he has the fluency, flexibility and authenticity in his ideas, opened with experience, respondent for the new-even though it is not logic in ideas and actions .

Love to discover things, speculative, love adventures, not feel fair risk in his ideas, actions, sensitive to details ,Appreciates aesthetics ideas and things, effective responses to external stimuli, whether ideas or feelings .

From the above research goals is achieved resulting hypotheses of research concerns: in the light of the results of statistical treatments used in all stages of research researcher was able to glean the following: using recreational motor story has a positive effect on innovation thinking (fluency - flexibility - authenticity) have a sample search Recreational use of experimental kinetic story has a positive impact better than traditional learning method to think innovation (fluency - flexibility authenticity) among a sample of experimental research.

Recommendations: in the light of the results, the researcher recommends the following recommendations:

using story recreational motor to improve thinking innovation (fluency - flexibility - authenticity) in 
kindergarten using recreational motor story to improve thinking innovation (fluency - flexibility - authenticity) in stages. Other ages

\section{References:}

1- Ibrahim Ahmed Alharthy (2004): Learning Thinking .Saudi Arabia,Alryad,Alshakry Library.

2- Elein Wadea Farag 1996: Experiences in Kides, Adults,MenshaatAlmaaref,Alexandria

3- Tahany Mohamed Abdelsalam 2001: Recreation Basis , Recreational Education, Dar Alfekr Alaraby, Cairo

4- Hassan Kamal Zaitoun 2002: Learning\&Teaching from the Structural Theory View, Cairo, Aalam Alkotob

5- Hanan Fayez Mahmoud Makhioun 2004: A Suggested Recreational Program and its effect in Developing Consciousness with Mental Retard Children, Unpublished Master Thesis, Faculty of Physical Education for Girls, Alexandria University

6- Soha Mohamed Fekry Mohamed2005: The Effect of two programs of Motor Story and Small Games on the Expressing Ability,Children Attention

7- Laila KaramAldein 2002: Scientific Thinking Development with Children, Arab League General Secretary, The Consulting Technical Committee for Arab Childhood,Cairo.
8- Mohamed Alhamahmy, Aida Abdelaziz 1998: Recreation between Theory and Apply. Edition 2,Book Center for Publish, Cairo.

9- Mohamed Abdelraheim Ads 2006: School and Thinking Learning, Sixth Edition, Amman ,DarAlfekr for Printing \&Publishing.

$10-$

http://www.childhood.gov.sa/vb/showthread.php?p=2860

11- Fink.L Dee (2005). “Integrated course design”. Marsh. http://www.idea.k- state.edu/papers/Idea_Paper_42.pdf Kenneth .M .(2001): Secondary Instructional Methods Bronco .MWC .Communications - INC.

12- Renzulli. J. (2004) .A practical system for Identifying gifted and talented students. http//:www.sp.vcom .edu. 18.

13- Shaffer.\&Mack.T (1998). "Cooperative learning helps educators teach about the Vietnam War. The Social Studies professional". News Letter of National Council For the Social Studies. 150.

14- Torrance . E. (1972): Can We Teach Children To Think Creativity. Journal of Creativities Behaviors . Vol. (6) .No.(2).

15- Yann . S (2000): The Effect Collaborative Problem Solving on Individual Ability .Paper Presented at The Annual Proceeding or Selected Research and Development October. 